\title{
Assembly of Adenoviruses
}

\author{
BO SUNDQUIST, EINAR EVERITT, LENNART PHILIPSON AND STEFAN HOGLUND \\ Department of Microbiology, The Wallenberg Laboratory, Uppsala University, Uppsala, Sweden
}

Received for publication 13 November 1972

\begin{abstract}
Sodium dodecyl sulfate-polyacrylamide gel electrophoresis of purified incomplete particles of adenoviruses type 2 and 3 revealed that core proteins V and VII and capsid proteins VI, VIII, and X were absent in these particles, but they contained polypeptides not present in complete particles. Two types of incomplete particles were observed in the electron microscope, appearing as deoxyribonucleic acid-less particles with single discontinuities in the capsid structure (about $80 \%$ ), or more amorphous particles resembling hexon aggregates (about 20\%). The amount of incomplete and complete particles increased in parallel during the infectious cycle. Detectable amounts were found at $13 \mathrm{~h}$ with a maximum rate of synthesis for both particles at $24 \mathrm{~h}$ after infection. ${ }^{3} \mathrm{H}$-labeled amino acids were incorporated into incomplete particles without a detectable lag period, but the label appeared in complete particles with a 60 - to 80 -min lag. Early after the pulse in pulse-chase experiments, the radioactivity was higher for incomplete particles than for complete particles and leveled off before the activity of complete particles reached a maximum. In the adenovirus type 2 system, pulse-chase experiments suggested a precursor-product relationship between incomplete and complete particles. After a short pulse, $19 \mathrm{~h}$ postinfection, entrance of ${ }^{3} \mathrm{H}$-labeled amino acids into the hexon polypeptide of complete particles was delayed for $80 \mathrm{~min}$, but no delay was observed for the labeling of the hexon polypeptide of incomplete particles. The core polypeptides appear in complete particles without a delay, also suggesting that incomplete particles were precursors to complete particles. Incorporation of ${ }^{3} \mathrm{H}$-labeled amino acids into the hexon polypeptide of complete and incomplete particles was drastically decreased by inhibition of protein synthesis with emetine. However, the uptake of label into core proteins of complete particles was only decreased to $50 \%$ on inhibition of protein synthesis. The results suggest that incomplete particles are intermediates in virus assembly in vivo and that the assembly of capsid polypeptides into incomplete and complete particles is dependent on continuing protein synthesis.
\end{abstract}

The structure of adenoviruses is complex, including an outer capsid with at least seven polypeptides arranged in icosahedral symmetry with distinct hexons and pentons (reference 11; E. Everitt, B. Sundquist, U. Petterson, and L. Philipson, Virology, in press). The genome is associated with two additional polypeptides as an internal core structure (reference 11; Everitt et al., Virology, in press). The mechanism of assembly of these complex virions is not known although kinetic studies have revealed that the assembly of the multimeric individual hexons and pentons may be thermosensitive events $(12,15)$. Newly synthesized core polypeptides are more rapidly associated with the virion during assembly than the polypeptides of the outer capsid (5). An in vitro assembly system has been described, in which viral deoxyribonucleic acid (DNA) from infected, arginine-depleted cells was assembled into virions with the aid of extracts from infected nonstarved cells (22). The temporal relationship between the appearance of core and capsid structures in assembly has not been determined in this in vitro system.

The relationship between core structures, incomplete particles and intact virions has, however, been reinvestigated in several other viral systems. Phillips and collaborators have provided evidence suggesting that the ribonucleic acid (RNA)-less 73s particles of poliovirions observed in vivo are precursors of intact virions (17). Recent reports on the assembly of SV40 virus may also indicate that some of the incomplete particles are precursors of intact virions $(13,14)$.

The mechanism of bacteriophage head assembly, originally thought from electron microscope data (6) to involve a capsid assembly on the outside of DNA condensates, has recently been reinterpreted with the aid of assembly mu- 
tants. Although the issue is still unsettled, it is possible that the empty phage head is formed before injection of phage DNA $(7,10)$.

The present study which reports on the protein composition of incomplete and complete particles of adenoviruses type 2 and 3 reveals that the incomplete particle contains polypeptides distinct from those contained in intact virions. Furthermore, the incomplete particles lack the polypeptides associated with the DNAcontaining core. This study also provides suggestive evidence for a precursor-product relationship between incomplete and complete particles. Finally, the in vivo assembly process seems to be dependent on an active protein synthesis.

\section{MATERIALS AND METHODS}

Cell and virus infection. HeLa cells and $\mathrm{KB}$ cells were grown in Spinner cultures in Eagle Spinner medium (2) with $7 \%$ calf serum as described previously (3). The prototype strains of adenoviruses type 2 and 3 were used in the present study. Their source was reported in previous communications $(3,19)$. Synchronized, one-step growth conditions were obtained by infecting with a multiplicity of 150 fluorescent focus-forming units (FFU) per cell or 1,000 to 2,000 particles per cell, as described previously (3).

Pulse labeling and chase conditions. Infected cells were centrifuged at $37 \mathrm{C}$ for $5 \mathrm{~min}$ at $3,500 \times g$ and suspended in a modified Eagle Spinner medium with $7 \%$ dialyzed calf serum at cell densities of $0.8 \times 10^{6}$ to $2 \times 10^{6}$ cells per ml. The medium contained $120 \mu \mathrm{M}$ arginine, $80 \mu \mathrm{M}$ valine, and $80 \mu \mathrm{M}$ leucine, which is a 10 -fold reduction of the normal concentrations used. After equilibration for $10 \mathrm{~min}$ at $37 \mathrm{C},{ }^{3} \mathrm{H}$-arginine $(5 \mu \mathrm{Ci} / \mathrm{ml}),{ }^{3} \mathrm{H}$-valine $(5 \mu \mathrm{Ci} / \mathrm{ml})$, and ${ }^{3} \mathrm{H}$-leucine $(5 \mu \mathrm{Ci} / \mathrm{ml})$ were added, and, after a 5 -min pulse, the cells were centrifuged, diluted to cell densities of $3 \times 10^{5}$ to $5 \times 10^{5}$ cells per ml with serum containing Eagle Spinner medium supplemented with unlabeled arginine, valine, and leucine to a 50 -fold excess over the concentration used during the pulse. To stop further protein synthesis, emetine (at $10 \mu \mathrm{g} / \mathrm{ml}$ ) was added after the ${ }^{3} \mathrm{H}$ amino acid pulse in some experiments.

Cells were harvested at varying time intervals during the chase and sedimented for $5 \mathrm{~min}$ at $3,500 \times g$, suspended in $0.01 \mathrm{M}$ tris(hydroxymethyl)aminomethane (Tris)-hydrochloride, $p \mathrm{H}$ 8.1 , and frozen at $-20 \mathrm{C}$.

Purification of complete and incomplete particles. Virus purification was performed essentially as described previously (3). Infected cells were harvested $48 \mathrm{~h}$ postinfection, centrifuged at 1,500 $\times g$ for $15 \mathrm{~min}$, suspended in $0.01 \mathrm{M}$ Tris-hydrochloride $(p \mathrm{H} \mathrm{8.1)}$ and frozen at $-20 \mathrm{C}$. After thawing, the cell suspension was sonically treated for $30 \mathrm{~s}$ in the cold, followed by centrifugation at $25,000 \times g$ for $15 \mathrm{~min}$. The supernatant fluid was extracted with Freon and purified on a gradient cushion of $\mathrm{CsCl}$ from 1.2 to $1.4 \mathrm{~g} / \mathrm{ml}$. The virus material was collected and separated on a preformed gradient of $\mathrm{CsCl}(1.35-1.28 \mathrm{~g} / \mathrm{ml})$ for $16 \mathrm{~h}$ at $180,000 \times g$. Complete particles could be separated from incomplete particles in this step, and each of them were separately resedimented on the same type of gradient. Incomplete particles were further purified by centrifugation on 15 to $30 \%$ sucrose gradients formed on a cushion of $\mathrm{CsCl}(1.40 \mathrm{~g} / \mathrm{ml})$ for $60 \mathrm{~min}$ at 150,000 $\times g$. The material accumulating at the interphase on the cushion was rebanded on a self-generating $\mathrm{CsCl}$ gradient. Both virions and incomplete particles were dialyzed against $10 \%$ glycerol in $0.01 \mathrm{M}$ Tris-hydrochloride $(p \mathrm{H} \mathrm{7.4}), 1 \mathrm{mM} \mathrm{MgCl} 2$, and $0.5 \%$ n-butanol. In some experiments with adenovirus type 2, where the amount of incomplete particles was low, the nuclear fraction of infected cells was sedimented on 10 to $25 \%$ sucrose gradients in $1 \mathrm{M} \mathrm{NaCl}, 20 \mathrm{mM}$ Tris-hydrochloride $(p \mathrm{H} \mathrm{8.1)}$ at $71,000 \times g$ for 75 to $85 \mathrm{~min}$. The nuclear fraction was obtained by breaking the cells with a tight-fitting Dounce homogenizer in the presence of $0.5 \%$ detergent (Nonidet P-40). Nuclei were washed and resuspended in $0.05 \mathrm{M}$ Tris-hydrochloride $(p \mathrm{H}$ 8)-2 mM EDTA and broken by ultrasonic treatment at $0 \mathrm{C}$ for $15 \mathrm{~s}$. The detailed procedure to release virus associated structure from infected cells was reported earlier (8).

Quantitation of incomplete and complete virion particles. The second $\mathrm{CsCl}$ gradient was eluted through a flow cell mounted in a Gilford spectrophotometer, and the amount of particles, expressed as optical density (OD) at $280 \mathrm{~nm}$, was calculated by measuring the areas of the peaks for incomplete and complete particles. For a more direct comparison of the amount of complete and incomplete particles, the $O D$ at $280 \mathrm{~nm}$ of the latter was multiplied by 1.6. This factor was determined from the relation of $O D$ at $280 \mathrm{~nm}$ and protein content of the two fractions measured by the Lowry procedure (9).

Extraction of the basic proteins of adenovirions. The basic proteins associated with the core and the outer capsid of the adenovirion were isolated by a method involving extraction of virions in $2.0 \mathrm{M} \mathrm{NaCl}$ in $5 \mathrm{M}$ urea buffered with $0.1 \mathrm{M}$ citrate buffer ( $p \mathrm{H} 3.4)$ and separation of the proteins on analytical polyacrylamide gels in $5 \mathrm{M}$ urea and $0.1 \mathrm{M}$ citrate buffer at $p \mathrm{H}$ 3.4. The detailed procedure is in the process of being published (Everitt et al., Virology, in press).

Protein determination. Protein was determined by the Lowry method (9) with bovine serum albumin as standard. Samples were dialyzed against $0.05 \mathrm{M} \mathrm{NaOH}$ prior to analysis.

Analytical sodium dodecyl sulfate gels. Analytical sodium dodecyl sulfate (SDS)-polyacrylamide gel electrophoresis (SDS gels) was performed as described elsewhere (Everitt et al., Virology, in press).

Electron microscopy. Incomplete particles both from $\mathrm{CsCl}$ and sucrose gradients were analyzed by electron microscopy according to the procedures reported in a previous communication (19). All samples were fixed with $5 \%$ glutaraldehyde (1). Excess fixative was removed by dialysis 
against $0.1 \mathrm{M} \mathrm{NH}_{4}$-acetate ( $p \mathrm{H}$ 6.7). Negative staining with uranyl acetate at $p \mathrm{H} 4.6$ and ammonium molybdate at $p \mathrm{H} 7.0$ were used in parallel.

Isotopes and chemicals. ${ }^{3} \mathrm{H}$-arginine $(20$ $\mathrm{Ci} / \mathrm{mM}) ;{ }^{3} \mathrm{H}$-valine $(6 \mathrm{Ci} / \mathrm{mM})$, and ${ }^{3} \mathrm{H}$-leucine (40 $\mathrm{Ci} / \mathrm{mM}$ ) were obtained from New England Nuclear Corp. (Boston, Mass.). Emetine-HCl was obtained from Sigma Chemical Co. (St. Louis, Mo.). Radioactive material was precipitated with cold $10 \%$ trichloroacetic acid, and acid-precipitated material was collected on nitrocellulose filters. The filters were washed with 10 $\mathrm{ml}$ of $80 \%$ ethanol, ethanol-ether $(1: 1)$, and ether, respectively, air dried, and counted in a toluene-based scintillation fluid.

\section{RESULTS}

Host cell contamination of incomplete particles. Since incomplete particles of adenovirus type 3 have been shown to contain at least one polypeptide not present in complete virions $(11,19)$, it was essential to quantitate the host cell contamination in the incomplete particles. Complete virions of adenovirus type 2 have previously been shown to contain less than $0.01 \%$ of host cell protein (3). The same purification method was used in the present study, including an additional sucrose gradient for the incomplete particles as described in Materials and Methods.

HeLa cells infected with adenovirus type 3 were mixed with ${ }^{3} \mathrm{H}$-amino acid-labeled, uninfected HeLa cells, and both types of particles were purified. Radioactivity in the purified material was determined (Table 1), and there was a low level of host cell contamination for incomplete particles, around $0.01 \%$. A contamination around $0.01 \%$ was confirmed for complete particles. These results suggest that the purification steps utilized were sufficiently discriminatory to study the polypeptide pattern of $i^{\text {ncomplete particles. The recovery of complete }}$ and incomplete particles through the purification scheme was between 45 to $50 \%$ for both types of particles.

Polypeptide composition of incomplete and complete particles from adenovirus types 2 and 3. The polypeptides of incomplete and complete particles from adenovirus type 2 and 3 were first analyzed on SDS gels. The incomplete particles were always present in cells infected with type 3 virus in amounts comparable to those of complete virions, but the incomplete particles could only be found in minute amounts for type 2 virus. The SDS gel electrophoresis patterns are shown in Fig. 1. The polypeptide pattern for complete virions of type 3 (Fig. 1C) and type 2 (Fig. 1A) are similar and contain the same number of polypeptides. The polypeptide Va peak in type 3 virus was probably a dimer of polypeptide VII as shown before (Everitt et al., Virology, in press). The migration rate of polypeptides III, IIIa, and IV differed significantly between the two types of virions. Incomplete virions from both types had additional polypeptides designated $\mathrm{A}, \mathrm{B}, \mathrm{C}, \mathrm{D}$, and $\mathrm{E}$ (Fig. 1B and D) and appeared to lack the core polypeptide VII. Band A and D migrated with a rate similar to that of polypeptides V and VI, respectively.

The basic protein compositions of both virions and incomplete particles were examined by extracting both types of particles from type 2 and 3 with the acid-high salt urea method, and these extracts were analyzed on acid urea-citrate acrylamide gels as described in Materials and Methods. The pattern for type 2 and type 3 virions on these gels (Fig. 2) shows that polypeptides V, VI, VII, VIII, and X could be extracted as previously was demonstrated for adenovirus type 2 (Everitt et al., Virology, in press), but the rate of migration of individual polypeptides differed between the two serotypes.

TABLE 1. Contamination with host cell proteins of compiete and incomplete particles of adenovirus type 3

\begin{tabular}{|c|c|c|c|c|c|}
\hline \multirow{2}{*}{ Particles } & \multicolumn{4}{|c|}{$\begin{array}{c}\text { Acid-insoluble radioactivity of }{ }^{3} \mathrm{H} \text {-amino acid-labeled extracts from } \\
\text { uninfected cells (counts } / \mathrm{min} \text { ) }\end{array}$} & \multirow{2}{*}{$\begin{array}{c}\text { Final } \\
\text { recov- } \\
\text { ery }^{a} \\
(\%)\end{array}$} \\
\hline & Mixture $^{b}$ & $\begin{array}{l}\text { First } \mathrm{CsCl} \\
\text { gradient }\end{array}$ & Sucrose gradient & $\begin{array}{l}\text { Final } \mathrm{CsCl} \\
\text { gradient }\end{array}$ & \\
\hline $\begin{array}{l}\text { Virions } \\
\text { Incomplete particles }\end{array}$ & $\begin{array}{l}3.5 \times 10^{6}(100)^{c} \\
3.5 \times 10^{6}(100)\end{array}$ & $\begin{array}{l}8,140(0.22) \\
6,150(0.17)\end{array}$ & $\begin{array}{ll}175 & (0.05) \\
220 & (0.006)\end{array}$ & $\begin{array}{rr}50(0.001) \\
165(0.005)\end{array}$ & $\begin{array}{l}40-50 \\
40-50\end{array}$ \\
\hline
\end{tabular}

a The final recovery of complete and incomplete particles was determined in reconstruction experiments with added purified labeled ${ }^{14} \mathrm{C}$-particles.

$b$ The different columns correspond to different steps in the purification scheme described in Materials and Methods.

c The figures within parentheses refer to the percentage of host cell contamination. 


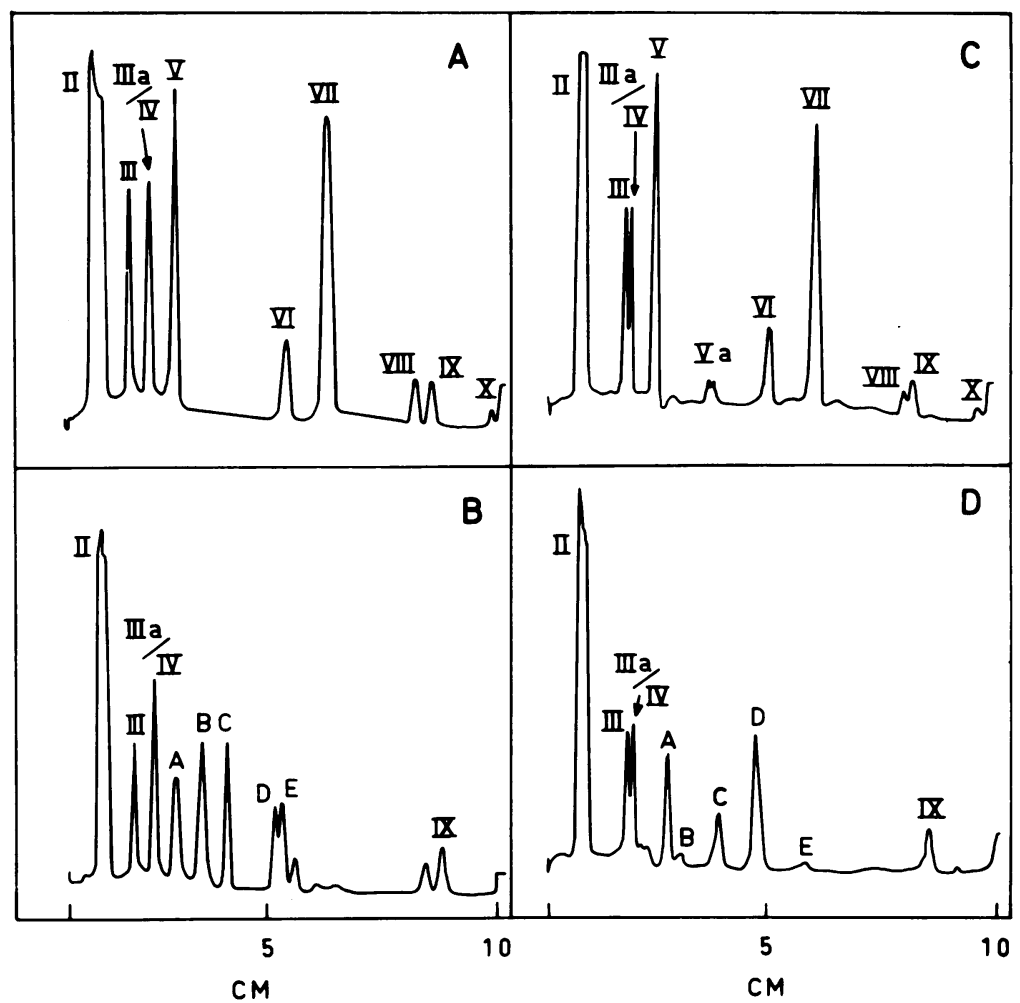

Fig. 1. Polypeptide patterns of incomplete and complete particles of adenovirus type 2 and 3 . Incomplete and complete particles from adenovirus type 2 and 3 were purified as described in Materials and Methods and analyzed on $15 \%$ SDS-polyacrylamide gels. The gels were stained with Coomassie blue and scanned in a Gilford spectrophotometer at $550 \mathrm{~nm}$. The anode is to the right, and the absorbance is given in arbitrary units. The peaks are numbered according to the nomenclature of Maizel (1971). A, Polypeptide pattern of adenovirus type 2-complete particles. B, Adenovirus type 2-incomplete particles. $C$, Adenovirus type 3-complete particles. D, Adenovirus type 3-incomplete particles.

No bands could be detected in the gels when extracts from incomplete particles were examined. Maizel et al. (11) previously showed that polypeptides V and, probably, VII were absent in incomplete virions, and both these proteins are associated with the core (reference 11; Everitt et al., Virology, in press). In addition, proteins VI, VIII, and X could not be recovered in incomplete particles, as shown here. When the ratios of the areas of the peaks corresponding to protein III (pentonbase) and protein II (hexon) were compared in complete and incomplete particles, it was found that the amount of protein II was significantly decreased in incomplete particles. Both adenovirus type 2 and 3 showed lowered ratios for polypeptides II and III in incomplete compared to complete particles.

Electron microscopy of incomplete virions from adenovirus type 2 and 3 . Incomplete virions were purified as described in Materials and Methods. After the last $\mathrm{CsCl}$ gradient they were fixed with $5 \%$ glutaraldehyde to stabilize the structure and examined in the electron microscope. No complete virions could be observed (Fig. 3), but one could distinguish two distinct classes of incomplete particles. The most abundant structure had an outline similar to complete virions (Fig. 3C), but the negative stain, uranylacetate, penetrated into the particles (Fig. 3E). The outer capsid contour was broken in some places, and some of the particles appeared similar to the pentonless particles observed after selective removal of the peripentonal region from the virion (18). The outer diameter of these particles, which constituted $80 \%$ of the population, was the same as for intact virions.

The second class of particles, which amounted to around $20 \%$ of the total, was more amorphous and appeared to be a conglomerate of hexon subunits with less defined shape of the outer capsid (Fig. 3B and D). The diameter of these structures appeared larger than for complete virions. 


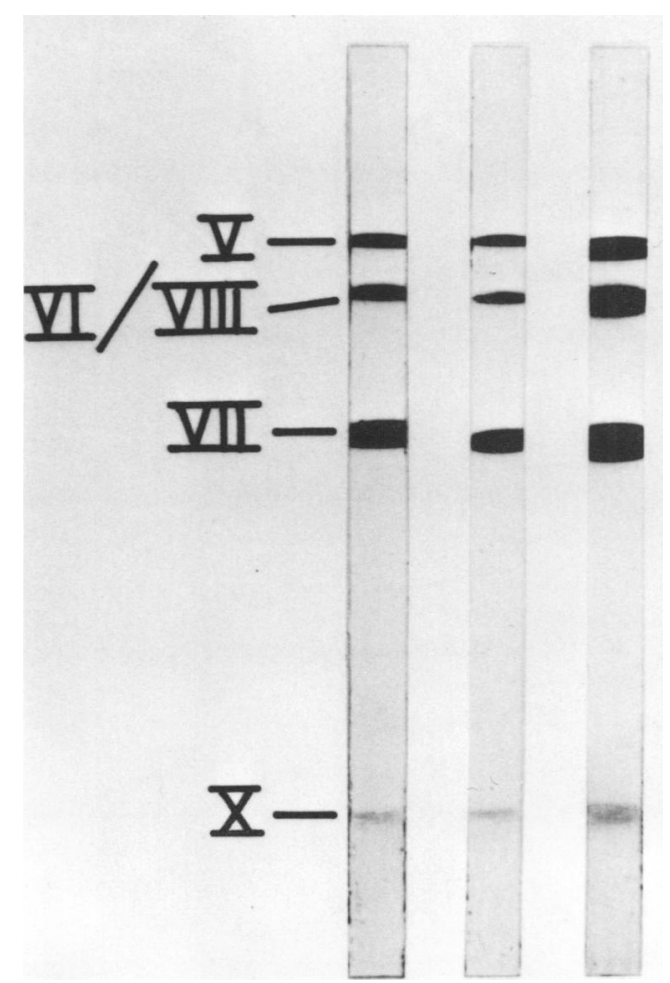

Fig. 2. Analytical acid-urea-polyacrylamide gels of complete particles of adenovirus type 2 and 3 . Purified complete particles from adenovirus type 2 and type $\$$ were extracted with the high-salt, acid urea method, and the extracts were analyzed on polyacrylamide gels in $5 \mathrm{M}$ urea and $0.1 \mathrm{M}$ citrate buffer at $p H$ 3.4. The cathode is at the bottom of the gels. The polypeptides are numbered according to Maizel (1971) and the proteins were identified in a previous communication (Everitt et al., Virology, in press). Left, Extracts of adenovirus type 2 virions; middle, extracts of adenovirus type 3 virions; and right, a mixture of virion extracts of type 2 and 3 .

Incomplete particles from adenovirus type 2 prepared from sucrose gradients to minimize the osmotic effects of $\mathrm{CsCl}$ showed the same two structures as described for adenovirus type 3 . No difference in structure between incomplete particles of type 2 and type 3 could be observed.

The growth curve of complete and incomplete adenovirus particles. Incomplete viral particles may either arise by breakdown of assembled virions $(13,14)$ by false assembly or as an intermediate in viral assembly $(10,13,14)$. The first two alternatives may infer a differential rate of appearance between complete and incomplete particles during growth.

The kinetics of the appearance of complete and incomplete particles was first studied by ana- lyzing the optical density of the two bands from $\mathrm{CsCl}$ gradients at different times of the growth cycle. HeLa cells were infected at a multiplicity of $150 \mathrm{FFU} /$ cell with adenovirus type 3. Samples were taken at different times postinfection, the two types of particles were separated on the second $\mathrm{CsCl}$ gradient, and the optical density pattern was recorded in a Gilford spectrophotometer and quantitated as described in $\mathrm{Ma}$ terials and Methods.

As shown in Fig. 4, the amounts of complete and incomplete particles are roughly the same in adenovirus type 3 after correction for the difference in DNA content of the two types of particles. They each accumulate exponentially at the same rate, starting around $13 \mathrm{~h}$. The maximum rate was reached at $24 \mathrm{~h}$ postinfection.

To study the temporal relationship between synthesis of incomplete and complete particles, cells infected with adenovirus type 3 for $21 \mathrm{~h}$ were continuously labeled with a mixture of radioactive arginine, valine, and leucine, as described in Material and Methods. Samples were taken at different times after the labeling, the two types of particles were highly purified, and the specific activity determined was expressed in counts per minute per microgram of protein. Fig. 5 shows that the incomplete particles are labeled before the complete particles. There is no lag period for the increase in specific activity of the incomplete particles, but there is a lag period of 60 to $80 \mathrm{~min}$ before the label enters the virions. These results suggest that the incomplete particles are formed prior to the virions.

Pulse-chase analysis of complete and incomplete particles. Pulse-chase experiments were performed next to determine if incomplete particles are in fact intermediates in virion assembly.

Cells were infected with adenovirus type 3 , and at $19 \mathrm{~h}$ postinfection the cells were labeled for 5 min with a mixture of radioactive arginine, valine, and leucine as described in Materials and Methods. At varying times during the chase with a 50-fold excess of unlabeled amino acids, virus and incomplete particles were purified, and the radioactivity in each fraction from the first $\mathrm{CsCl}$-gradient was determined as described in Materials and Methods. Fig. 6 shows that the radioactivity in incomplete particles again increased faster than for the complete virions and without a detectable lag, but a lag period of 60 to $80 \mathrm{~min}$ was observed prior to the increase in radioactivity in virions. The radioactivity in the fractions containing incomplete particles later decreased, whereas the radioactivity in 


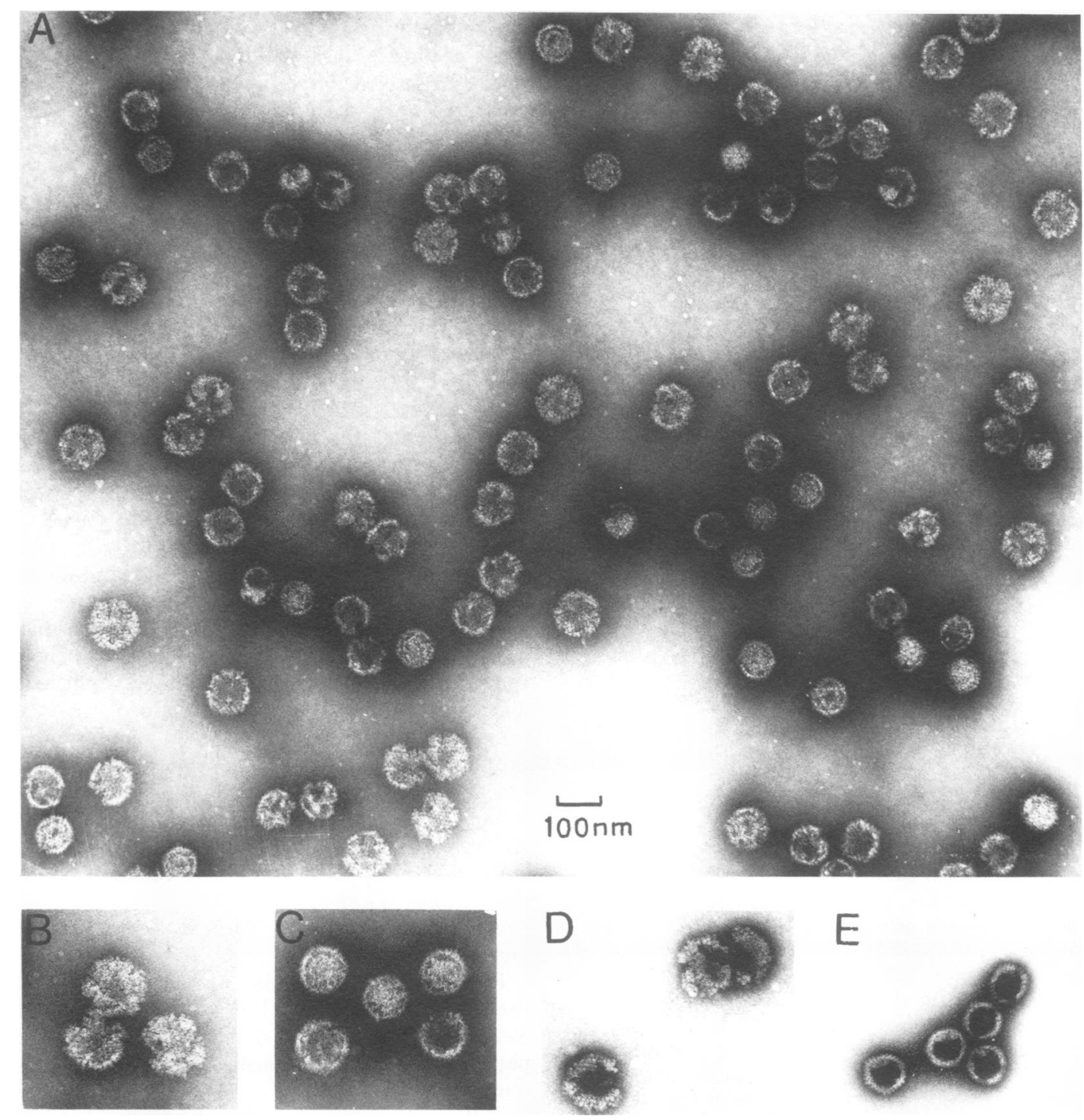

Fig. 3. Electron microscopy of incomplete particles from adenovirus type \$. The particles were fixed with $5 \%$ glutaraldehyde and contrasted with uranylacetate at $p H 4.6(A, B, C)$ and with ammonium molybdate at $p H 7.0$ ( $D$ and $E$ ). Panels $C$ and $E$ show the DNA-less virus-like particles with single discontinuities in the outer capsid. Panels $B$ and $D$ show the diffuse particles similar to hexon conglomerates. Magnification for $B, C, D$, and $E, \times 000,000$.

complete virions was still increasing after the total radioactivity of the gradients had reached a plateau (300 $\mathrm{min})$, i.e., at the time the pulse was effectively chased. These results suggest that at least a fraction of the incomplete particles is a precursor in the assembly of complete adenovirus type 3 virions.

Similar experiments were performed with adenovirus type 2, which has low amounts of incomplete particles. The turnover of incomplete particles into virions may hopefully be more rapid than for adenovirus type 3 , which has a large pool of incomplete particles.

$\mathrm{KB}$ cells were infected with adenovirus type 2, pulse-labeled with the three ${ }^{3} \mathrm{H}$-amino acids at $15 \mathrm{~h}$ after infection, and chased with cold amino acids as described for adenovirus type 3 above. Cell samples were withdrawn, and a nuclear fraction was prepared for analysis of complete and incomplete particles on sucrose gradients 


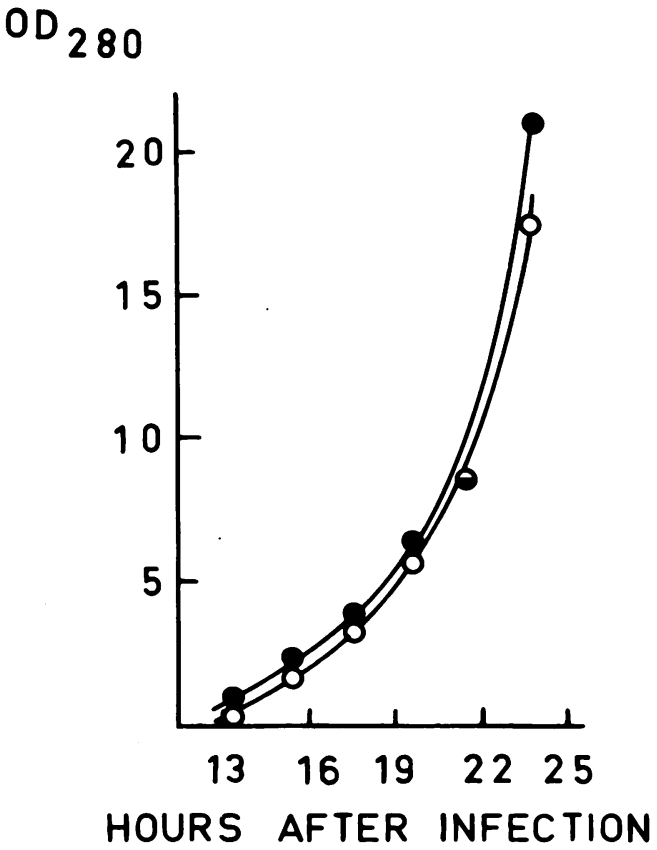

FIg. 4. Quantitation of incomplete (O) and complete (O) particles after infection of HeLa cells with adenovirus type $\$$ under one-step growth conditions. Incomplete and complete particles were purified by $\mathrm{CsCl}$ gradient centrifugations and eluted through a Gilford recording spectrophotometer. The quantity was calculated from the peak area in the elution profile.

as described in Materials and Methods. This technique resolves complete and incomplete particles (8).

The material from nuclear extracts of adenovirus type 2-infected cells, corresponding to the position of incomplete particles in the sucrose gradients, was analyzed in the electron microscope after fixation in $5 \%$ glutaraldehyde, and the same structures as reported for adenovirus type 3 (Fig. 3) were identified (data not shown).

Fig. 7 shows the radioactivity pattern at three selected times during the chase after a 5 -min pulse with ${ }^{3} \mathrm{H}$-amino acids. The overall pattern clearly indicates that the incomplete particles are intermediates in the assembly of complete adenovirus type 2 virions.

The precursor-product relationship is more clearly demonstrated in Fig. 8, which shows that the rise in radioactivity of incomplete particles precedes, and the decrease coincides with, the rise in radioactivity of intact virions. A late decrease of radioactivity in complete particles was observed at $24 \mathrm{~h}$ postinfection when nuclear leakage of infected cells was increasing.

Inhibition of protein synthesis and virion

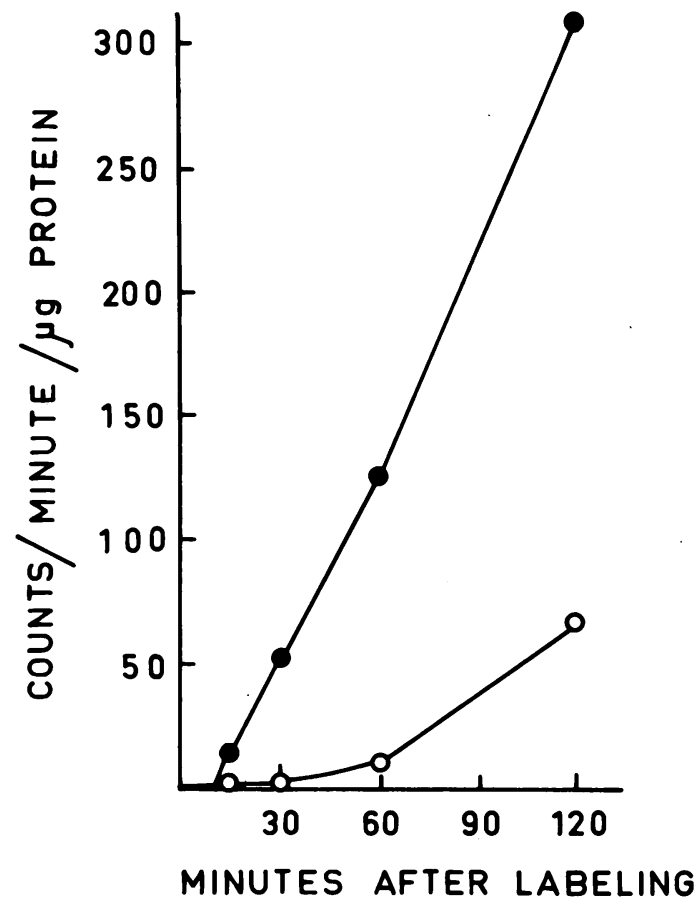

Fig. 5. Continuous label of incomplete and complete particles. The specific activity (counts per minute per microgram of protein) of incomplete (O) and complete (O) particles from adenovirus type $s$ at different time intervals after continuous label with ${ }^{3} H$-amino acids at 21 after infection.

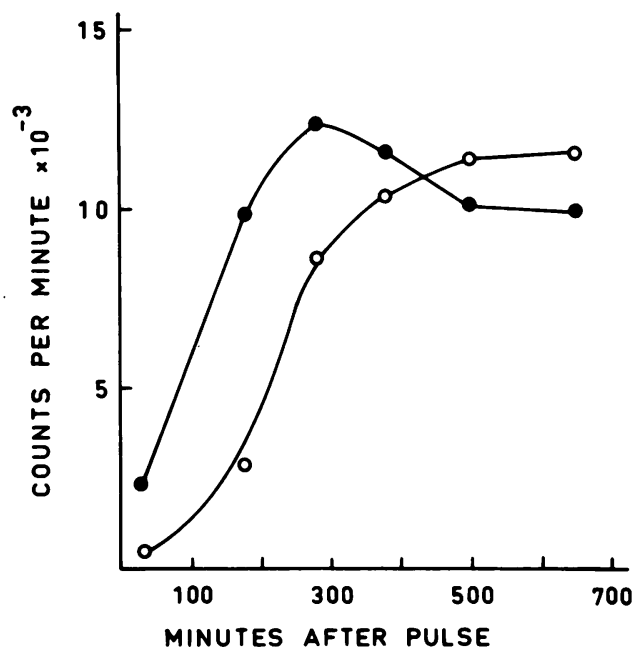

Fig. 6. Pulse-chase labeling kinetics of incomplete and complete particles of adenovirus type 3 . HeLa cells were infected with adenovirus type $\$$ and pulse-labeled for 5 min with ${ }^{3} \mathrm{H}$-amino acids at $19 \mathrm{~h}$ postinfection followed by a chase with a 50-fold excess of unlabeled amino acids. Symbols: 0 , incomplete particles; $O$, complete particles. 


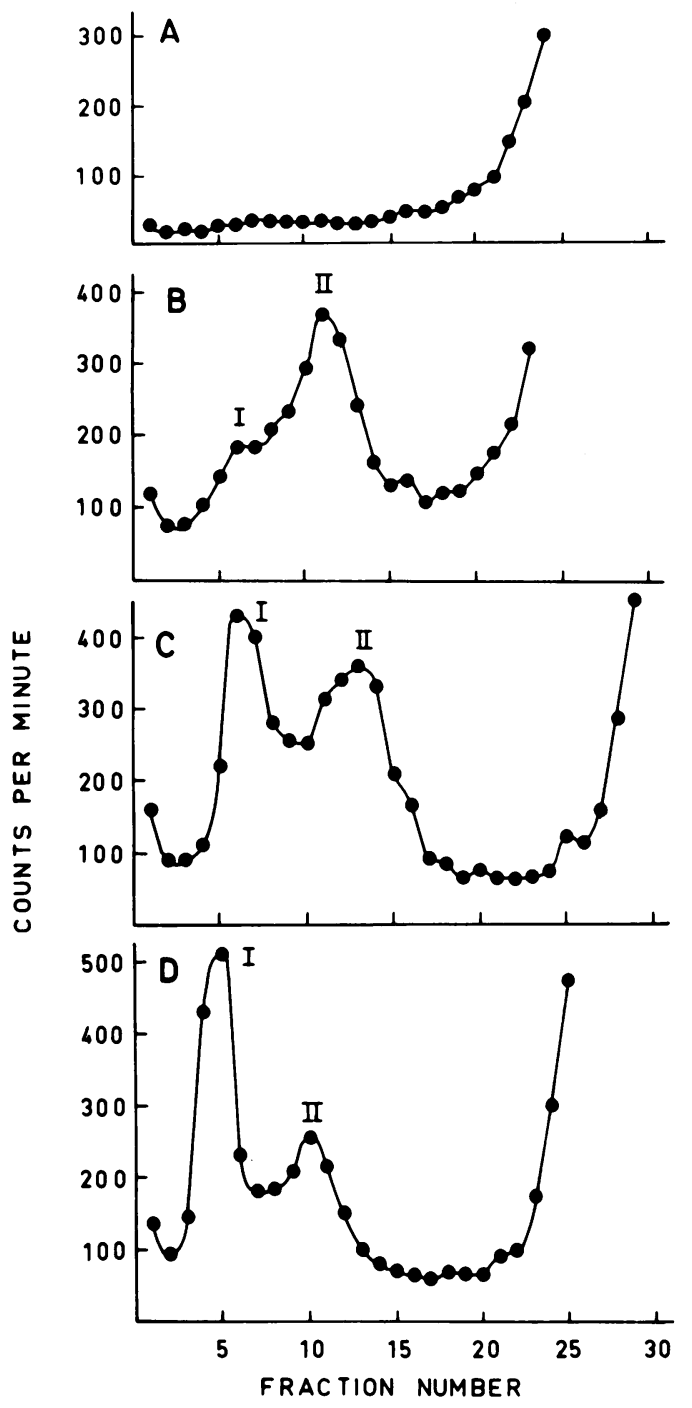

FIG. 7. High salt-sucrose gradients (10-25\%) centrifuged at $71,000 \times g$ for $85 \mathrm{~min}$ of nuclear extracts from adenovirus type 2 -infected $K B$ cells which were pulse labeled for 5 min with ${ }^{3} \mathrm{H}$-amino acids at $15 \mathrm{~h}$ after infection followed by a chase with a 50-fold excess of unlabeled amino acids. $A$, $A$ gradient from uninfected cells; $B, 1.0 \mathrm{~h} ; C, 2.5 \mathrm{~h}$; and $D, 3.5 h$ after the chase. Peak I corresponds to complete particles and peak II to incomplete particles.

assembly. Since incomplete particles appeared to be precursors to complete virions, it was of interest to further corroborate this hypothesis by following the kinetics of entrance of different polypeptides into virions and incomplete particles. Preferably, this should be performed with inhibition of protein synthesis after the pulse to avoid reutilization of the isotope.

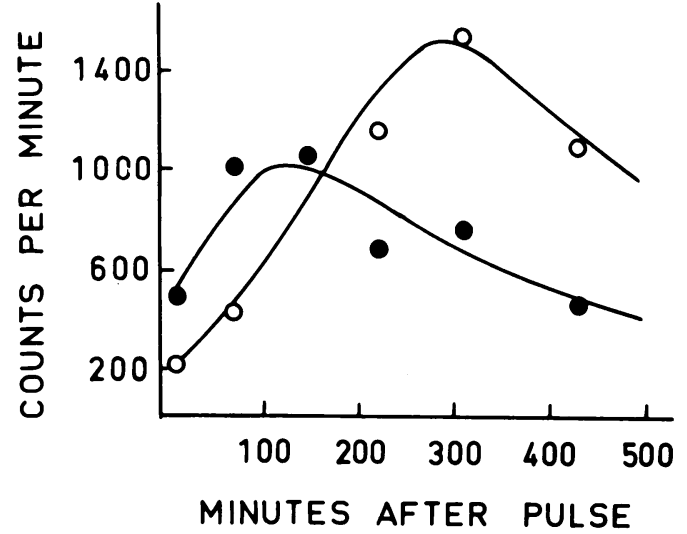

FIG. 8. Precursor-product relationship between incomplete and complete particles of adenovirus type 2. The data in the pulse chase experiment with adenovirus type 2 illustrated in Fig. 7 was compiled by plotting the radioactivity peaks indicated by the bars against time. Symbols: $\mathrm{O}$, incomplete particles; O, complete particles.

The effect of inhibition of protein synthesis was therefore studied using emetine at a concentration of $10 \mu \mathrm{g} / \mathrm{ml}$ which inhibits protein synthesis by $99 \%$ (4). Similar results were also obtained with cycloheximide at $50 \mu \mathrm{g} / \mathrm{ml}$.

At $19 \mathrm{~h}$ after a type 3 infection, cells were pulse labeled for 5 min with the three ${ }^{8} \mathrm{H}$-amino acids, and the cells were divided into two equal samples. In one sample, protein synthesis was terminated with emetine $(10 \mu \mathrm{g} / \mathrm{ml})$, and both samples were chased with a 50 -fold excess of unlabeled amino acids. The two types of virus particles were purified at varying times after the pulse, and their specific radioactivity was determined.

Fig. 9 shows that a block in protein synthesis had a drastic effect on assembly of both incomplete and complete virions, but the effect is possibly more pronounced for incomplete particles. The specific activity of incomplete and complete particles under inhibition of protein synthesis was only $45 \%$ of the values for virions from uninhibited cells.

The sequential entrance of polypeptides into incomplete and complete particles. Since adenoviruses contain core proteins associated with the DNA within the capsid, it is possible to use another approach to support the hypothesis that the incomplete particles are precursors to intact virions. Horwitz et al. (5) demonstrated that the core polypeptide VII was more rapidly assembled into intact virions than the hexons, which, in the light of results reported above, may suggest that incomplete particles are precursors. 


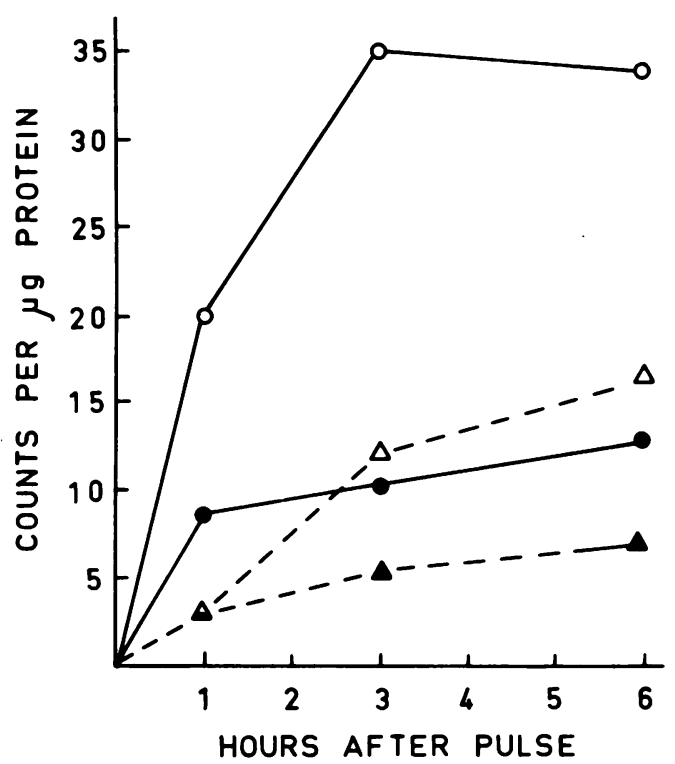

Fig. 9. Inhibition of protein synthesis and specific activity (counts per minute per microgram of protein) of adenovirus type 3 particles. After a 5-min pulse with ${ }^{8} \mathrm{H}$-amino acids at $19 \mathrm{~h}$ after infection followed by a chase with a 50-fold excess of unlabeled amino acids, protein synthesis was inhibited by adding emetine $(10 \mu \mathrm{g} / \mathrm{ml})$ immediately after the pulse. Symbols: $O$, incomplete particles without inhibition; $\bigcirc$, incomplete particles at inhibition; $\Delta$, complete particles without inhibition; $\mathbf{\Delta}$, complete particles at inhibition.

To gain further insight in the process of viral assembly, cells infected with adenovirus type 3 for $19 \mathrm{~h}$ were pulse-labeled for $5 \mathrm{~min}$ with three ${ }^{3} \mathrm{H}$-labeled amino acids and chased by the addition of a 50 -fold excess of unlabeled amino acids. In one sample, emetine was added at 10 $\mu \mathrm{g} / \mathrm{ml}$. Samples were taken out at different times after the pulse, and the two types of particles were purified and analyzed on SDSpolyacrylamide gels for radioactivity. Gel patterns similar to those presented in Fig. 1 were obtained, and the total radioactivity from each individual peak was integrated and plotted as the percentage of the value obtained for that peak at $6 \mathrm{~h}$ of chase with an excess of amino acids, a time when the chase was complete.

Fig. 10 shows several facts which may be important for viral assembly in vivo. First, the radioactivity in the polypeptides of incomplete particles is always higher than that of complete particles, as already shown above in pulse-chase experiments. Secondly, inhibition of protein synthesis affects the assembly of the incomplete particles and especially the assembly of hexon into incomplete particles. The assembly of the
INCOMPLETE PARTICLES

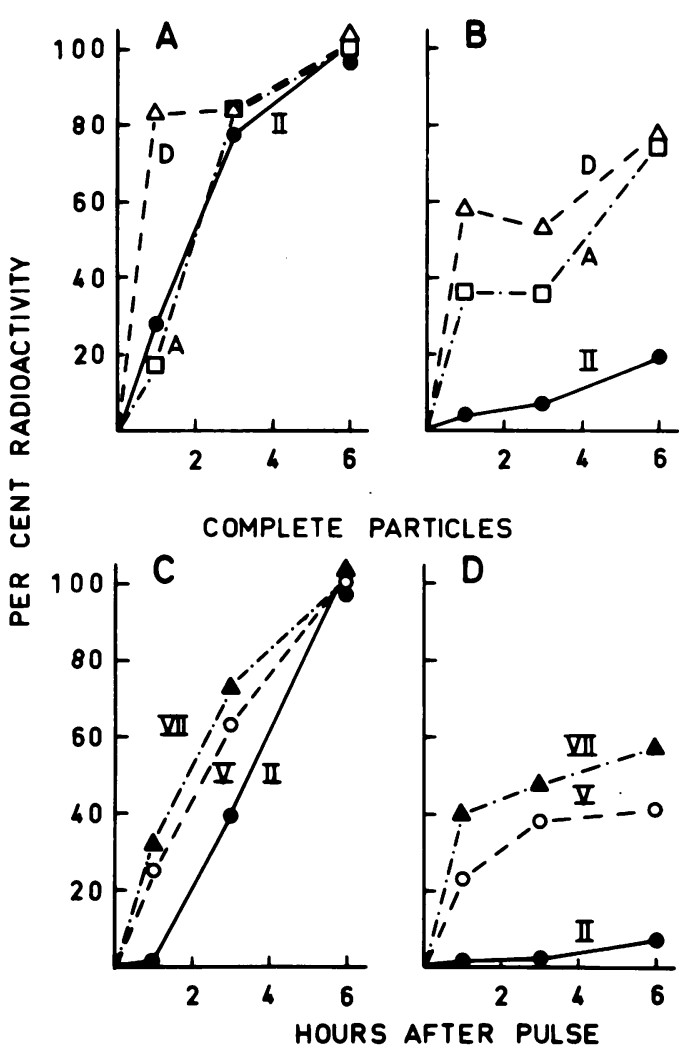

FIG. 10. Assembly of virus polypeptides into virus particles after inhibition of protein synthesis. Virus particles were purified and analyzed on SDS gels. The activity from each peak was calculated, and the values were expressed as percentage of the value at 6 h after the pulse in samples without inhibition. Part A, Incomplete particles without inhibition; part $B$, incomplete particles with inhibition; II, hexon; $A$, protein $A, D$, protein $D$ (See Fig. 1). Part $C$, complete particles without inhibition; Part D, complete particles with inhibition; II, hexon; $V$, protein $V ; V I I$, protein VII.

polypeptides $\mathrm{A}$ through $\mathrm{E}$ into incomplete particles and the assembly of core polypeptides $\mathrm{V}$ and VII into intact virions were less sensitive to inhibition of protein synthesis than the assembly of outer capsid polypeptides. Finally, and most important, assembly of core polypeptides into virion precedes the entrance of the outer capsid polypeptides, in spite of the fact that hexons are rapidly assembled into incomplete particles.

\section{DISCUSSION}

The separation of incomplete from complete particles in the adenovirus type 3 system was simple because of their difference in bouyant 
density, 1.34 and 1.30 , respectively, but it is more difficult to purify incomplete particles from host cell contaminants. The procedure used, combining equilibrium density and rate zonal centrifugation, gave a product with less than $0.01 \%$ of host cell contaminants in reconstruction experiments, although the recovery was 45 to $50 \%$ (Table 1). The polypeptide pattern of the incomplete particles revealed at least three but probably five polypeptides, which were not present in intact virions. The core polypeptides $\mathrm{V}$ and VII and in addition polypeptides VI, VIII, and $\mathrm{X}$ were absent in incomplete particles. The lack of core polypeptides in incomplete particles and the presence of at least one nonvirion polypeptide in these structures was demonstrated recently (19). Both the disk SDS gels and the urea extraction method utilized in this study may resolve polypeptides better than continuous SDS gels $(11,21)$.

Electron microscopy revealed that the incomplete particles were not homogeneous and probably represent at least two different classes, one appearing as a conglomerate of hexon subunits in an irregular structure without a distinct shape (Fig. 3B and D). This structure appears to be more flattened and has a larger diameter on the grids than the virions. The other class appears as particles lacking the core structures, but with a discontinuity in the outer capsid (Fig. 3C and E). It is not possible to discern if the holes are located in a vertex region, but, since the hexon-to-penton ratio was lower in incomplete compared to complete particles, it is possible that the break in the outer capsid resides in one or several of the triangular facets of the virion. The latter type of particles is at least four times more abundant in the purified incomplete particles from the adenovirus type 2 and 3 suggesting that it accounts for the majority of particles also in vivo, since the recovery from the first to last purification step was 45 to $50 \%$. Highly purified and characterized incomplete particles were required to study if they were intermediates in assembly in vivo.

It was first demonstrated (Fig. 4) that the incomplete particles in the adenovirus type 3 system were increasing in absolute amount concurrent with the increase in virions, suggesting that these particles were not created primarily by breakdown of virions late in the infectious cycle. With continuous and pulse-chase labeling it was possible to demonstrate that the amino acid label entered virions with a lag period and also with a slower rate than for incomplete particles of both adenovirus type 2 and 3 . A precursor-product relationship between incomplete and complete particles could be established with adenovirus type 2, a virus type with a minute pool of incomplete particles. Pulse chase experiments with adenovirus type 3 , even though the pool of incomplete particles in this system is large, suggested such a relationship at least for a fraction of the particles. Since the morphology of the incomplete particles of the two virus types were the same, it appears justified to conclude that incomplete capsid structures are precursors to the virions in the adenovirus system. Similar findings have been reported for other virus systems such as poliovirus (17) and SV40 virus $(13,14)$. It has also been suggested recently that the phage head in T4 phage may be assembled prior to the entrance of phage DNA (9).

All kinetic experiments involving purification of intermediates may, however, be criticized since it cannot be demonstrated unequivocally that the purification method did not cause release of DNA from the intermediates. The methods used in the experiments reported in Fig. 7 and 8, where it was suggested that incomplete particles of adenovirus type 2 were intermediates to intact virions, were designed to counteract this criticism. The cells were opened with nonionic detergent, the nuclei with sonic treatment, and the particles were separated by sucrose gradient centrifugation and fixed before electron microscopy. Furthermore, the different polypeptide composition and the precursor-product relationship in pulse chase experiment appears to establish that the incomplete particles are intermediates in the assembly reaction. In addition to the insertion of viral DNA, the assembly of complete virions from incomplete particles also appears to involve an exchange of internal proteins.

Finally, it is of interest that the assembly reaction requires intact protein synthesis and that the formation of incomplete particles was more sensitive to inhibition than the formation of mature virions. This was in contrast to other animal viruses, like picornaviruses, where inhibition of protein synthesis has been utilized to determine the gene order in the RNA genome (20). The sensitivity to inhibition of protein synthesis makes it also difficult to understand the in vitro assembly of adenoviruses (22) unless the factors provided by the infected cells are an intact protein synthesizing system. One factor may, however, be rate limiting and required in stoichiometric amounts at assembly, a condition which predicts that we have differential translation of different messenger RNA in adenovirus infected cells, as recently suggested from studies of translation of adenovirus proteins during inhibition of protein synthesis (15). 


\section{ACKNOWLEDGMENTS}

The skillful technical assistance provided by $\mathrm{S}$. Rosén and I. Hubinette is gratefully acknowledged. We also want to thank Uno Lindberg and Clark Tibbetts for valuable criticism and help with this manuscript.

This work was supported by grants from the Swedish Cancer Society and the Wallenberg Foundation, Stockholm, Sweden.

\section{LITERATURE CITED}

1. Baltimore, D., and A. Huang. 1968. Isopycnic separation of subcellular components from polio-infected and normal HeLa cells. Science 162:572574.

2. Eagle, H. 1959. Amino acid metabolism in mammalian cell cultures. Science 130:432-437.

3. Everitt, E., B. Sundquist, and L. Philipson. 1971. Mechanism of the arginine requirement for adenovirus synthesis. I. Synthesis of structural proteins. J. Virol. 5:742-753.

4. Grollman, A. P. 1968. Inhibition of protein biosynthesis. V. Effects of emetine on protein and nucleic acid biosynthesis in HeLa cells. J. Biol. Chem. 243:4089-4094.

5. Horwitz, M. S., M. D. Scharff, and J. V. Maizel, Jr. 1969. Synthesis and assembly of adenovirus 2 . I. Polypeptide synthesis, assembly of capsomeres, and morphogenesis of the virion. Virology 39:682694.

6. Kellenberger, E., A. Ryter, and J. Sechaud. 1958. Electron microscope study of DNA-containing plasms. II. Vegetative and mature phage DNA as compared with normal bacterial nucleoids in different physiological states. J. Biophys. Biochem. Cytol. 4:671-678.

7. King, J. 1968. Assembly of the tail of bacteriophage T4. J. Mol. Biol. 32:231-262.

8. Lonberg-Holm, K., and L. Philipson. 1969. Early events of virus-cell interaction in an adenovirus system. J. Virol. 4:323-338.

9. Lowry, O. H., N. J. Rosenbrough, A. L. Farr, and R. J. Randall. 1951. Protein measurements with the Folin phenol reagent. J. Biol. Chem. 193:265275.
10. Luftig, R. B., W. B. Wood, and R. Okinaka. 1971. Bacteriophage T4 head morphogenesis. On the nature of gene 49-defective heads and their role as intermediates. J. Mol. Biol. 57:555-573.

11. Maizel, J. V., Jr., D. O. White, and M. D. Scharff. 1968. The polypeptides of adenovirus. II. Soluble proteins, cores, top components and the structure of the virion. Virology 36:126-136.

12. Okubo, C. K., and H. J. Raskas. 1971. Thermosensitive events in the replication of adenovirus type 2 at $42^{\circ}$. Virology 46:175-182.

13. Ozer, H. L. 1972. Synthesis and assembly of simian virus 40. I. Differential synthesis of intact virions and empty shells. J. Virol. 9:41-51.

14. Ozer, H. L., and P. Tegtmeyer. 1972. Synthesis and assembly of simian virus 40 . II. Synthesis of the major capsid protein and its incorporation into viral particles. J. Virol. 9:52-60.

15. Perlman, S., M. Hirsch, and S. Penman. 1972. Utilization of messenger in adenovirus-2-infected cells at normal and elevated temperatures. Nature (London) 238:143-144.

16. Pettersson, U. 1971. Structural proteins of adenoviruses. VI. On the antigenic determinants of the hexon. Virology 43:123-136.

17. Phillips, B. A. 1971. In vitro assembly of poliovirus. II. Evidence for the self-assembly of $14 \mathrm{~S}$ particles into empty capsids. Virology 44:307-316.

18. Prage, L., U. Pettersson, S. Höglund, K. LonbergHolm, and L. Philipson. 1970. Structural proteins of adenoviruses. IV. Sequential degradation of the adenovirus type 2 virion. Virology 12:341358.

19. Prage, L., S. Höglund, and L. Philipson. 1972. Structural proteins of adenoviruses. VIII. Characterization of incomplete particles of adenovirus type 3. Virology 49:745-757.

20. Rekosh, D. 1972. Gene order of the poliovirus capsid proteins. J. Virol. 9:479-487.

21. Russell, W. C., and J. J. Skehel. 1972. The polypeptides of adenovirus-infected cells. J. Gen. Virol. 15:45-57.

22. Winters, W. D., and W. C. Russell. 1971. Studies on the assembly of adenovirus in vitro. J. Gen. Virol. 10:181-194. 